\title{
Características de um aço microligado forjado API 5L
}

\author{
Characteristics of one forging microalloyed \\ steel API 5L
}

\author{
André Itman Filho ${ }^{1}$, Suzana Souza Silva Scardua ${ }^{1}$, \\ Rosana Vilarim da Silva ${ }^{1}$, João Batista Ribeiro Martins ${ }^{2}$
}

\begin{abstract}
${ }^{1}$ Propemm: Avenida Vitória, 1729, Jucutuquara - CEP 29040-780, Vitória-ES.
${ }^{2}$ ArcelorMittal: Av. Brigadeiro Eduardo Gomes, 930 Jardim Limoeiro - CEP29163-970, Serra-ES. e-mail: andrei@ifes.edu.br, epmsuzana@gmail.com1, joaobatista.martins@ arcelormittal.com.br.
\end{abstract}

\begin{abstract}
RESUMO
Nos aços microligados da série API (American Petroleum Institute) utilizados na fabricação de dutos de grande diâmetro, a resistência mecânica deve ser suficiente para suportar as elevadas pressões do fluido transportado na indústria petroquímica. $\mathrm{O}$ aumento da resistência mecânica e da tenacidade para permitir a operação da linha em pressões mais elevadas, sem a ocorrência de colapso da estrutura, é o principal requisito para os aços utilizados nestes dutos. No Brasil, as empresas produzem estes aços por meio da laminação de tiras a quente ou chapas grossas, com adição de nióbio, titânio e vanádio, conforme os requisitos da norma API 5L. Considerando a complexidade geométrica dos componentes utilizados na indústria petroquímica, tais como flanges e centralizadores de tubos, é importante desenvolver um processo alternativo para fabricação de acessórios com as exigências desta norma. Dentro deste contexto e com o objetivo de avaliar novas técnicas de processamento, foi elaborado um aço com composição química similar à de um API 5L X70. O metal líquido foi vazado em uma lingoteira e forjado em barras com secção quadrada. As barras foram recozidas e amostras foram cortadas para confecção de corpos de prova que foram submetidos à têmpera e revenimento em diferentes temperaturas. As análises microestruturais e propriedades mecânicas de dureza e tração, após os tratamentos térmicos, foram comparadas às existentes na literatura para tubos de aços laminados. Os resultados mostram que as condições dos tratamentos térmicos são importantes para desenvolver uma rota alternativa de forjamento controlado, para aços com características da norma API 5L.
\end{abstract}

Palavras-chave: Aço microligado, tratamentos térmicos, forjamento de aço.

\begin{abstract}
In API (American Petroleum Institute) microalloyed steels used in the manufacture of large diameter pipelines, the mechanical properties must be sufficient to withstand the high pressure of the transported fluid in the petrochemical industry. The increased of yield strength and toughness to allow operation at higher line pressure, without collapse of the structure, is the main requirement for these steels. In Brazil, industries produce these steels by hot rolling of strips or plates, with the addition of niobium, titanium and vanadium, as the requirements of API 5L standard. Due to the geometric complexity of the components, such as flanges and pipes connections, it is important to develop an alternative process for the manufacture of these accessories. Regarding this context and in order to evaluate a new processing, one steel was developed with chemical composition as an API 5L X70. The liquid metal was poured into an ingot mold and forged bars were manufactured with square section. The bars were annealed and samples were cut. The samples were submitted to quenching and tempering at different temperatures. Hardness measurements, microstructural analysis and mechanical properties, after quenching and tempering treatments were compared with literature results for the rolled steel tubes. Preliminary results show that the heat treatments conditions are important to develop an alternative route by controlled forging for steels, with standard API 5L characteristics.
\end{abstract}

Keywords: Microalloyed steel, heat treatments, steel forging.

\section{INTRODUÇÃO}

Os aços da série API (American Petroleum Institute) são utilizados principalmente na construção de dutos 
para transporte de petróleo e gás natural via terrestre, ou para operações em grandes profundidades, onde suportam pressões de até 350 Bar em meio de cloretos, sulfetos e outros gases dissolvidos (HIPPERT, 2004). Para estes fins, os aços API devem apresentar resistência mecânica e à corrosão, tenacidade e soldabilidade adequada. $\mathrm{O}$ processo convencional destes aços é a laminação controlada.

No Brasil, a prospecção de petróleo em regiões profundas como o pré-sal, necessita o desenvolvimento de novos materiais e técnicas de processamento, capazes de atender às solicitações de projetos estruturais para transporte de óleo e gás. Nestes casos são necessários aços com elevada resistência mecânica e tenacidade, para suportar as elevadas pressões geradas pela coluna da água oceânica e a vazão de óleo e gás na tubulação. Atualmente, tubos com diâmetros elevados são utilizados onde a menor espessura da parede é desejada, para redução do peso, diminuição da quantidade de solda em cada junta e redução de custos.

Os vários aços para tubos, especificados pela norma API 5L, podem ser classificados como aços ARBL (Alta Resistência e Baixa Liga) e usualmente contêm nióbio, titânio e vanádio que garantem boa tenacidade à fratura, alta resistência à tração e resistência à fragilização por hidrogênio (HULKA, 2001). Tais propriedades são resultantes da combinação de uma microestrutura com grãos refinados, alta densidade de discordâncias e endurecimento por precipitação de carbonetos, nitretos e carbonitretos finamente dispersos na matriz. Na fabricação do aço API 5L X70 para confecção de tubos é utilizado o processo de laminação controlada seguido de resfriamento contínuo ou acelerado. Em componentes e acessórios com maior complexidade geométrica, tais como juntas e conexões para diferentes dimensões de tubos, a laminação não é a técnica mais adequada e o processo de forjamento pode ser uma técnica alternativa.

Atualmente, diversos flanges e conexões são produzidos pela técnica de forjamento (VALLOUREC \& MANESMANN TUBES, 2013). Este processo, muito utilizado na indústria automotiva, permite uma ampla faixa de dimensões e formas complexas com controle da microestrutura e propriedades mecânicas após tratamentos térmicos adequados.

Considerando o grande interesse da Petrobrás em desenvolver fornecedores no Brasil, o objetivo desta pesquisa foi a elaboração de barras quadradas forjadas de um aço microligado, que atenda as exigências da norma API 5L. Para avaliar a qualidade do aço elaborado, as análises microestruturais e as propriedades mecânicas foram comparadas às de um tubo com $60 \mathrm{~cm}$ de diâmetro e espessura de $20 \mathrm{~mm}$, confeccionado com um aço comercial laminado API 5L X70.

\section{MATERIAIS E MÉTODOS}

O aço foi elaborado em um forno de indução com capacidade para $100 \mathrm{~kg}$, e composição química conforme a Tabela 1. O vazamento do metal líquido foi realizado em uma lingoteira de ferro fundido. Os lingotes foram aquecidos em torno de $1050{ }^{\circ} \mathrm{C}$, forjados com secção quadrada de $38 \mathrm{~mm}$ de lado por aproximadamente um metro de comprimento e resfriados ao ar.

Posteriormente as barras forjadas foram aquecidas a $930{ }^{\circ} \mathrm{C}$ e resfriadas no forno para homogeneização da microestrutura. Amostras cúbicas com $15 \mathrm{~mm}$ de aresta, cortadas de uma barra, foram aquecidas a 850 e $900{ }^{\circ} \mathrm{C}$, durante 30 minutos em um forno tipo mufla e resfriadas em água. Em seguida foram revenidas nas temperaturas de $150,250,350,450,500,550,600$ e $650{ }^{\circ} \mathrm{C}$ durante 40 minutos com resfriamento ao ar.

As medidas de dureza nas amostras recozidas a $930{ }^{\circ} \mathrm{C}$ e revenidas nas diferentes temperaturas foram realizadas em um durômetro modelo HP 250 a partir do método Rockwell, escala B, com pré-carga de 10 kgf. Os valores das Tabelas 2 e 3 representam a média de cinco medidas de dureza em cada amostra. Para caracterização microestrutural, as amostras foram lixadas e polidas conforme os métodos convencionais de preparação metalográfica. Para ataque químico foi utilizado Nital $2 \%$, com um tempo de aplicação de aproximadamente 30 segundos. As análises microestruturais foram realizadas por Microscopia Ótica Confocal (MOC) e Microscopia Eletrônica de Varredura (MEV).

Para determinar as propriedades mecânicas foram usinados corpos de prova retirados da direção longitudinal de uma barra recozida, conforme recomendação da norma API 5L e ASTM A370. Os corpos de prova foram aquecidos a 850 e $900{ }^{\circ} \mathrm{C}$, com resfriamento em água, e posteriormente revenidos a 250 e 450 ${ }^{\circ} \mathrm{C}$, com resfriamento ao ar. Estas temperaturas de revenimento foram escolhidas por apresentarem os valores mínimo e máximo de durezas obtidas na faixa de 150 a $650{ }^{\circ} \mathrm{C}$. Os ensaios de tração foram realizados em uma máquina universal EMIC DL10000, com velocidade do travessão de $1 \mathrm{~mm} / \mathrm{min}$.

\section{RESULTADOS}

A composição química do aço forjado e a de um tubo comercial laminado estão mostradas na Tabela 1. 
Tabela 1: Composição química do aço forjado e de um tubo laminado comercial API X70. Percentuais em massa.

\begin{tabular}{l|c|c|c|c|c|c|c|c|c|c|c}
\hline ELEMENTO & $\mathbf{C}$ & $\mathbf{S i}$ & $\mathbf{M n}$ & $\mathbf{P}$ & $\mathbf{S}$ & $\mathbf{C r}$ & $\mathbf{M o}$ & $\mathbf{N i}$ & $\mathbf{N b}$ & $\mathbf{T i}$ & $\mathbf{V}$ \\
\hline LAMINADO & 0,10 & 0,15 & 1,63 & 0,02 & 0,003 & 0,03 & 0,01 & 0,16 & 0,050 & 0,020 & 0,040 \\
\hline FORJADO & 0,11 & 0,09 & 0,33 & 0,03 & 0,02 & 0,37 & 0,05 & 0,40 & 0,081 & 0,013 & 0,010 \\
\hline
\end{tabular}

Na Tabela 2 são apresentados os valores da dureza Rockwell B para o aço microligado forjado após têmpera a $850{ }^{\circ} \mathrm{C}$ e revenimento em diferentes temperaturas (média de cinco medidas). A amostra recozida apresentou valores de $58 \pm 2 \mathrm{HRB}$ nas diferentes secções longitudinal, transversal e normal.

Tabela 2: Dureza do aço forjado após aquecimento a $850{ }^{\circ} \mathrm{C}$ com resfriamento em água e revenimento em diferentes temperaturas com resfriamento ao ar.

\begin{tabular}{c|c|c|c|c|c|c|c|c|c}
\hline Revenimento $\left({ }^{\circ} \mathrm{C}\right)$ & $*$ & $150^{\circ} \mathrm{C}$ & $250^{\circ} \mathrm{C}$ & $350{ }^{\circ} \mathrm{C}$ & $450^{\circ} \mathrm{C}$ & $500^{\circ} \mathrm{C}$ & $550^{\circ} \mathrm{C}$ & $600^{\circ} \mathrm{C}$ & $650{ }^{\circ} \mathrm{C}$ \\
\hline Dureza (HRB) & $98 \pm 2$ & $96 \pm 2$ & $95 \pm 2$ & $83 \pm 2$ & $81 \pm 3$ & $84 \pm 3$ & $91 \pm 3$ & $86 \pm 3$ & $81 \pm 3$ \\
\hline
\end{tabular}

\section{* Amostra sem revenimento.}

Na Tabela 3 são apresentados os valores da dureza em Rockwell B para o aço microligado forjado após têmpera a $900{ }^{\circ} \mathrm{C}$ e revenimento em diferentes temperaturas (média de cinco medidas).

Tabela 3: Dureza do aço forjado após aquecimento a $900{ }^{\circ} \mathrm{C}$ com resfriamento em água e revenimento em diferentes temperaturas com resfriamento ao ar.

\begin{tabular}{r|c|c|c|c|c|c|c|c|c}
\hline Revenimento $\left({ }^{\circ} \mathrm{C}\right)$ & $*$ & $150{ }^{\circ} \mathrm{C}$ & $250^{\circ} \mathrm{C}$ & $350^{\circ} \mathrm{C}$ & $450{ }^{\circ} \mathrm{C}$ & $500^{\circ} \mathrm{C}$ & $550^{\circ} \mathrm{C}$ & $600{ }^{\circ} \mathrm{C}$ & $650{ }^{\circ} \mathrm{C}$ \\
\hline Dureza (HRB) & $82 \pm 2$ & $84 \pm 2$ & $82 \pm 1$ & $79 \pm 3$ & $79 \pm 2$ & $80 \pm 2$ & $83 \pm 2$ & $82 \pm 1$ & $81 \pm 1$ \\
\hline
\end{tabular}

\section{* Amostra sem revenimento.}

Na Tabela 4 são apresentados os valores da tensão de escoamento, resistência à tração e alongamento para o aço forjado e tubo laminado (média de três ensaios). Os corpos de prova do aço forjado foram aquecidos a 850 e $900 \mathrm{oC}$, resfriados em água e revenidos nas temperaturas de 250 e $450 \mathrm{oC}$. O corpo de prova do tubo representa a condição de laminação controlada.

Tabela 4: Tensão de escoamento, resistência à tração e alongamento do aço forjado recozido a 930 oC, após têmpera (TEMP) e revenimento (REV) em diferentes temperaturas e do tubo comercial laminado como recebido.

\begin{tabular}{c|c|c|c|c}
\hline AÇO & TEMP X REV & $\sigma_{E}$ (MPA) & $\sigma_{\text {MAX }}$ (MPA) & AL(\%) \\
\hline Tubo Laminado & Recebido & $555 \pm 5$ & $645 \pm 6$ & $18 \pm 2$ \\
\hline Aco Forjado & Recozido & $333 \pm 5$ & $250 \pm 5$ & $33 \pm 2$ \\
\hline Aço Forjado & $850 \times 250^{\circ} \mathrm{C}$ & $528 \pm 10$ & $663 \pm 10$ & $8 \pm 2$ \\
\hline Aço Forjado & $850 \times 450^{\circ} \mathrm{C}$ & $510 \pm 12$ & $645 \pm 13$ & $9 \pm 1$ \\
\hline Aço Forjado & $900 \times 250^{\circ} \mathrm{C}$ & $610 \pm 10$ & $672 \pm 12$ & $7 \pm 1$ \\
\hline Aço Forjado & $900 \times 450^{\circ} \mathrm{C}$ & $590 \pm 11$ & $650 \pm 10$ & $8 \pm 2$ \\
\hline
\end{tabular}

Na Tabela 5 são apresentados os valores da tensão de escoamento, resistência à tração e alongamento 
mínimo conforme a norma API 5L.

Tabela 5: Valores da tensão de escoamento $\left(\sigma_{\mathrm{E}}\right)$, resistência à tração máxima ( $\left.\sigma_{\mathrm{MAX}}\right)$ e alongamento mínimo (ALMIN) para tubos confeccionados com o aço API X70.

\begin{tabular}{c|c|c|c}
\hline NORMA API 5L - API X70 & $\sigma_{\mathrm{E}}=485-635 \mathrm{MPa}$ & $\sigma_{\mathrm{MAX}}=570-760 \mathrm{MPa}$ & ALMIN $=16 \%$ \\
\hline
\end{tabular}

Nas figuras 1 a 6 são apresentadas as microestruturas características do tubo comercial obtido por laminação controlada, do aço forjado após recozimento a $930{ }^{\circ} \mathrm{C}$ e recozido com os tratamentos térmicos de têmpera e revenimento. As amostras são representativas da direção longitudinal do tubo e da barra.

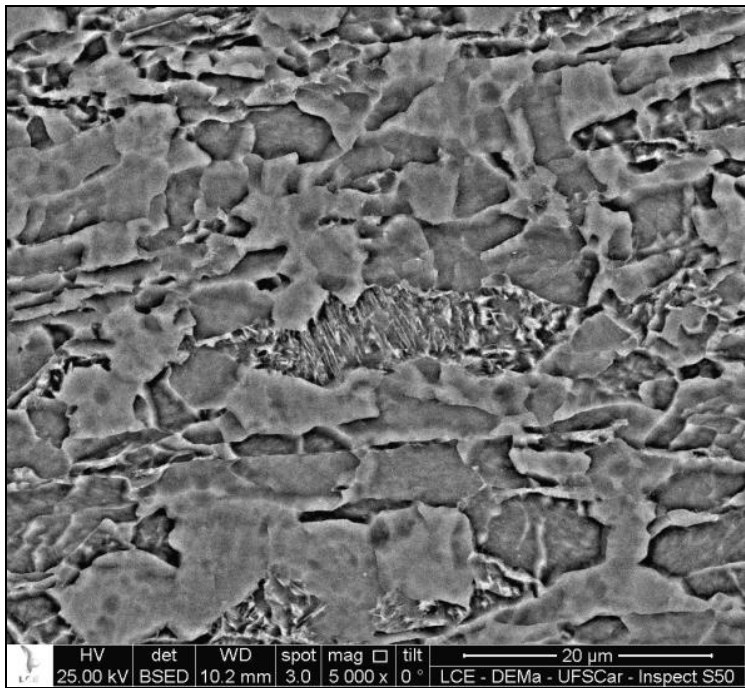

Figura 1: Aço do tubo comercial (Nital $2 \%$ - MEV).

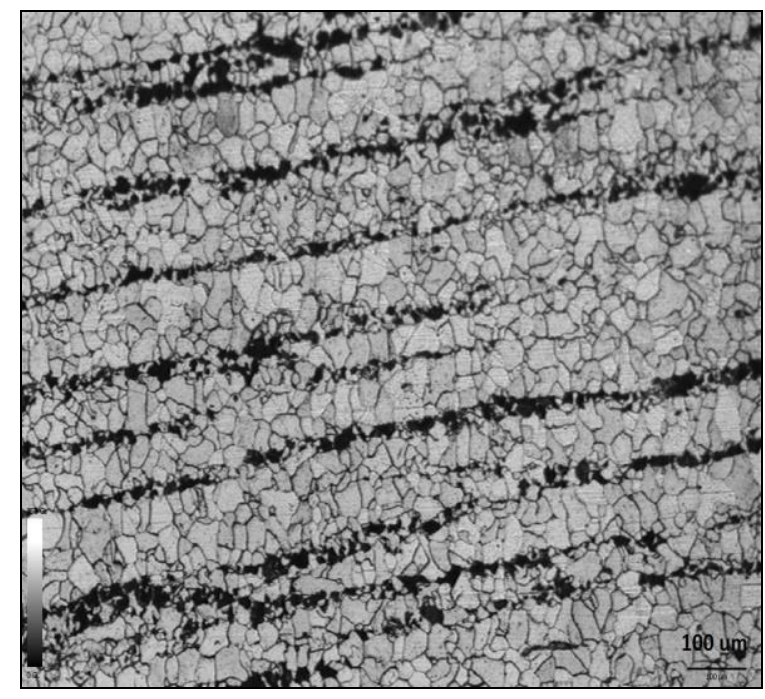

Figura 2: Aço forjado recozido (Nital 2\% - MOC).

Na Figura 1 é possível observar a presença de regiões bainíticas na matriz ferrítica obtida após o processo de laminação controlada. Na Figura 2 observa-se uma microestrutura homogênea de ferrita equiaxial ou poligonal e perlita alinhada, no aço forjado e recozido a $930{ }^{\circ} \mathrm{C}$ na direção longitudinal.

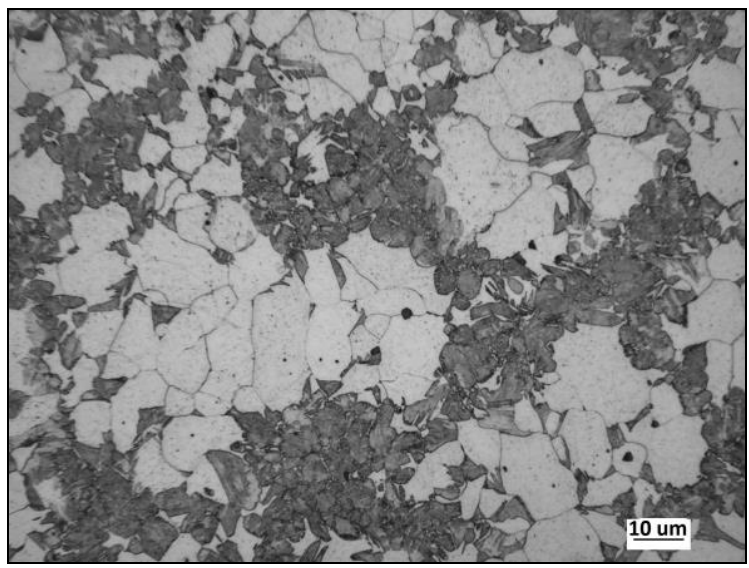

Figura 3: Aço forjado (Nital $2 \%$ - MOC).

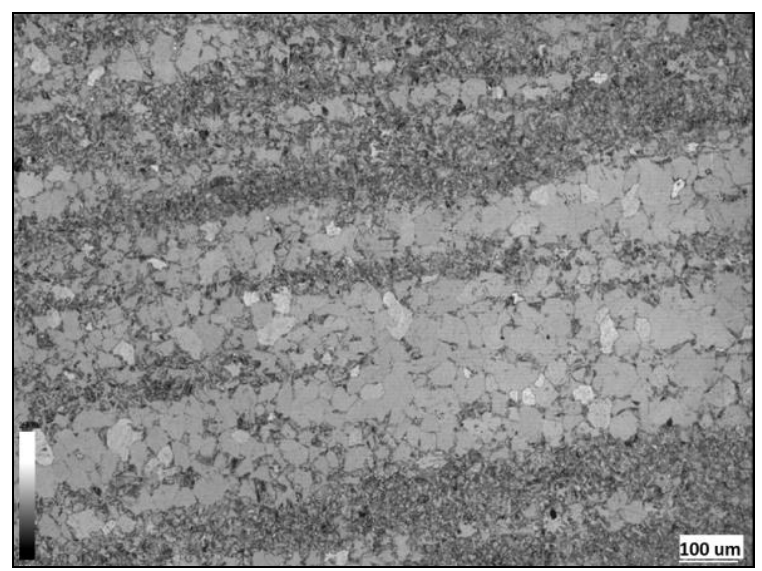

Figura 4: Aço forjado (Nital $2 \%$ - MOC).

Nas Figuras 3 e 4 são apresentadas as microestruturas do aço forjado após aquecimento a $850{ }^{\circ} \mathrm{C}$ e revenido a $250{ }^{\circ} \mathrm{C}$ e $450{ }^{\circ} \mathrm{C}$, respectivamente. É possível observar a estrutura perlítica alinhada de cor escura na matriz, pois a temperatura não foi suficiente para austenitização completa. Não houve alteração significativa da microestrutura após o revenimento. 
Nas Figuras 5 e 6 são apresentadas as microestruturas do aço forjado após têmpera a $900{ }^{\circ} \mathrm{C}$ e revenimento a 250 e $450{ }^{\circ} \mathrm{C}$, respectivamento. É possível observar os diferentes tipos de ferrita, alotriomórfica, acicular e Widmanstatten, além de bainita.

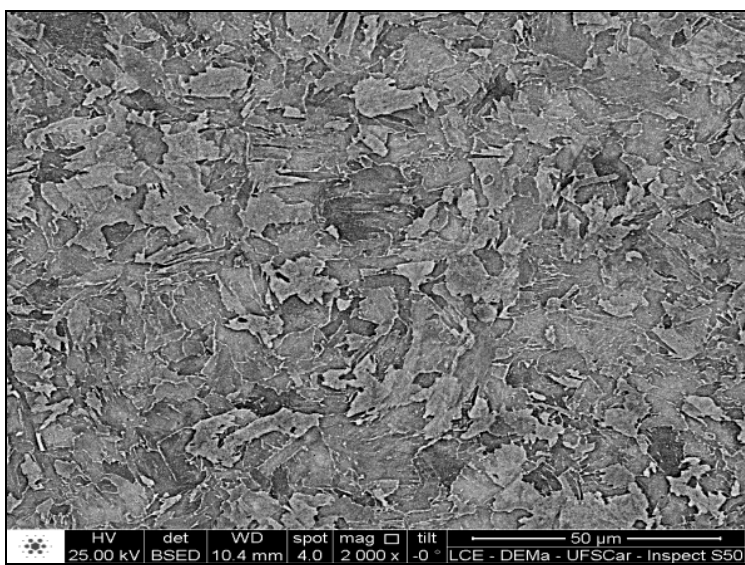

Figura 5: Aço forjado (Nital 2\% - MEV).

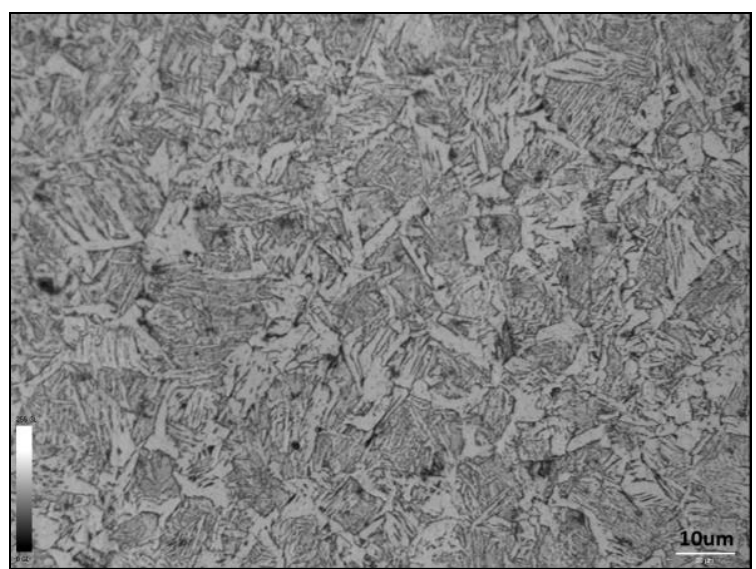

Figura 6: Aço forjado (Nital 2\% - MOC)

\section{DISCUSSÃO}

Quanto à composição química houve dificuldade no controle do fósforo e enxofre, pois há uma variação porcentual destes elementos nos ferros-ligas utilizados na elaboração do aço. No caso do manganês, atualmente são desenvolvidos aços com menor teor deste elemento, associado a teores de enxofre em torno de 10 ppm, para reduzir os sulfetos prejudiciais à tenacidade. É importante lembrar que os aços da série API 5L são padronizados pelas propriedades mecânicas e composição química, onde a exigência é para um valor máximo de $1,7 \%$ em peso de manganês. Com relação ao aumento de níquel e cromo, a razão foi a contaminação do refratário do forno com corridas anteriores, pois a empresa fornecedora do aço forjado produz principalmente aços inoxidáveis. Os maiores teores do cromo e níquel na composição química não prejudicam a qualidade do aço elaborado.

Com relação às durezas apresentadas nas Tabelas 2 e 3 não foi observada diferença significativa após revenimentos na faixa de 150 a $650{ }^{\circ} \mathrm{C}$, considerando a mesma temperatura de têmpera. No entanto, as durezas a $900{ }^{\circ} \mathrm{C}$ foram menores que a $850{ }^{\circ} \mathrm{C}$. Nesta última, o teor de carbono na austenita é maior do que $0,1 \%$ conforme análise do diagrama ferro-carbono e, portanto, após resfriamento houve a formação de martensita. $\mathrm{Na}$ amostra recozida os valores encontrados foram de $58 \pm 2$, independente da secção normal, transversal ou longitudinal medida. Da mesma forma, as microestruturas representativas destas direções são similares à da Figura 2, o que indica boa homogeneidade do material após o forjamento e recozimento. Como referência, a dureza encontrada na amostra do tubo laminado é igual a 96 \pm 1 HRB. Com o revenimento não houve mudança significativa na microestrutura do aço, embora as Tabelas 2, 3 e 4 mostrem a tendência de redução da dureza, das tensões de escoamento e resistência máxima à tração, com o aumento da temperatura deste tratamento. Na Tabela 4 é possível observar que embora os valores das tensões atendam a especificação, o alongamento encontrado é inferior ao exigido pela norma. Isto provavelmente ocorre em razão da variação quantitativa dos constituintes aciculares nas diferentes temperaturas de revenimento. É conhecido na literatura que o aumento da quantidade de ferrita acicular provoca a diminuição do alongamento (ZUO e ZHOU, 2015). Com a adequação das temperaturas e tempos de tratamento térmico, espera-se o controle efetivo da característica morfológica do material e das propriedades mecânicas exigidas pela norma API 5L.

De acordo com as análises microestruturais referentes ao tubo comercial, observa-se na Figura 1 a presença predominante da estrutura ferrítica com regiões de bainita, obtida no processo de laminação controlada. A amostra recozida apresentada na Figura 2 é caracterizada por uma microestrutura homogênea de ferrita equiaxial e perlita, típica de aços com baixo teor de carbono. É possível observar a presença de estruturas bandeadas de perlita em razão da segregação dos elementos de liga e orientação direcional do forjamento.

Como pode ser observado nas Figuras 3 e 4, após o tratamento térmico a $850{ }^{\circ} \mathrm{C}$, não houve a completa austenitização e as fases ferrítica e perlítica continuam presentes no aço. Nas amostras resfriadas rapidamente a transformação da austenita ocorre distante do equilíbrio e provavelmente promove o aparecimento do constituinte MA, de difícil visualização na microscopia convencional. 
Na Figura 5 e principalmente na Figura 6, com maior aumento, é possível observar a ferrita alotriomórfica nos contornos de grão associada à ferrita Widmanstatten e bainita. $\mathrm{Na}$ têmpera a $900^{\circ} \mathrm{C}$ seguida de revenimento a 250 e $450^{\circ} \mathrm{C}$, a amostra é austenitizada completamente e é observada a presença de constituintes aciculares, principalmente ferrita e bainita, após o resfriamento. Estes constituintes atuam como efetivas barreiras para a propagação intergranular de trincas e associados aos mecanismos de endurecimento secundário aumentam a resistência mecânica do material (YU, 2008). Este efeito é comum em aços de baixo e ultrabaixo carbono durante o resfriamento, onde a decomposição da austenita favorece estas morfologias (KRAUSS E THOMPSON, 1995). Nestes aços, mesmo com teores inferiores a $0,15 \%$ de $(\mathrm{Ti}+\mathrm{V}+\mathrm{Nb})$ é prevista a precipitação de carbonetos finamente dispersos na matriz, durante a transformação austenita/ferrita (GORNI, SILVEIRA e REIS, 2010).

É importante salientar que o comportamento da bainita e da ferrita acicular é diferente ao da martensita. A dureza da martensita diminui com o aumento da temperatura de revenimento, devido à liberação de carbono da estrutura tetragonal de corpo centrado, para formação de carbonetos. No caso da bainita e ferrita acicular, o carbono está na forma de carbonetos, minimizando o efeito de perda de dureza durante o revenimento (BHADESHIA, 2001).

De uma forma geral, a técnica de forjamento é uma rota importante para substituir a laminação, para confecção de componentes com geometrias diferentes das obtidas com a utilização de chapas. Com relação aos valores das propriedades mecânicas os resultados preliminares mostram que os de alongamento não atendem a norma API 5L X70. No entanto, espera-se que utilizando temperaturas de revenimento superiores será possível determinar as condições de processamento, para obter aços forjados com as características microestruturais e propriedades mecânicas dos laminados comerciais.

\section{CONCLUSÕES}

O tratamento térmico de recozimento permitiu homogeneizar a microestrutura e a dureza das diferentes direções de forjamento;

A temperatura de $850{ }^{\circ} \mathrm{C}$ não é suficiente para completa austenitização do aço e há permanência da perlita na microestrutura;

Na têmpera a $900{ }^{\circ} \mathrm{C}$, houve um acentuado aumento da dureza, justificado pela formação de constituintes displacivos tais como a ferrita acicular, ferrita Widmanstatten e bainita na microestrutura;

A presença de constituintes displacivos na microestrutura provoca aumento da tensão de escoamento e da resistência máxima à tração com redução do alongamento;

$\mathrm{O}$ aumento da temperatura de revenimento não altera significativamente os valores da dureza do aço.

\section{AGRADECIMENTOS}

Os autores agradecem à Finep e à Fapes pelo apoio financeiro e à Fundição Grupo Metal pelas amostras do aço forjado.

\section{BIBLIOGRAFIA}

[1] HIPPERT Jr., E., Investigação experimental do comportamento dúctil de aços API X70 e aplicações de curvas de resistência J- $\Delta$ a para previsão de colapso em dutos, Tese de D. Sc., Escola Politécnica - USP, São Paulo, SP, Brasil, 2004.

[2] HULKA, K. “Sour Gas Resistant Steel”, Niobium Information 18/01, Cia. Bras. Met. Mineração, pp. 8, 2001.

[3] CATÁlOGO DE PRODUTOS DO GRUPO VALLOUREC \& MANESMANN TUBES, Componentes tubulares forjados. Disponível em http://www.vmtubes.com.br/vmbinternet/filesmng.nsf/.pdf, acessado em novembro de 2013.

[4] ZUO, X., ZHOU, Z. "Study of Pipeline Steels with Acicular Ferrite Microstructure and Ferrite-bainite Dual-phase Microstructure”, Materials Research, v.18, n.1, pp. 36-41, Jan-Feb. 2015.

[5] YU, H., "Influences of microstructure and texture on crack propagation path of X70 acicular ferrite pipeline steel", Journal of University of Science and Technology, v. 15, n. 6, pp. 683-687, Dez 2008.

[6] KRAUSS, G., THOMPSON, S.W., "Ferritic microestructures in continuously cooled low-and ultralowcarbon steel", ISIJ International, v. 35, n. 8, pp. 937-945, Mai. 1995.

[7] GORNI, A.A., da SILVEIRA, J.H.D., REIS, J.S., "Metalurgia dos aços microligados usados em tubos soldados de grande diâmetro", Corte \& Conformação de Metais, pp. 50-63, Mar. 2010.

[8] BHADESHIA, H.K.D.H., Bainite in Steels, 2 ed., Londres, 2001. 